\title{
COMPARATIVE ANALYSIS OF THE COMPRESSIVE STRENGTH OF HOLLOW SANDCRETE BLOCKS WITH DIFFERENT CAVITIES ARRANGEMENT
}

\author{
J. C. Agunwamba ${ }^{1,}{ }^{*}$, J. C. Ezeokonkwo ${ }^{2}$ and M. E. Onyia ${ }^{3}$ \\ 1,2,3 Department of Civil EngineERING, University of NigERIa, NSUKKA, ENUGU STATE, NIGERIA \\ E-mail addresses:1 ${ }^{1 j o n a h . a g u n w a m b a @ u n n . e d u . n g, 2 j o s e p h a t . e z e o k o n k w o @ u n n . e d u . n g, ~}$ \\ 3ebieonyia64@yahoo.com
}

\begin{abstract}
Previous analysis showed that cavity size and number on one hand and combinations thickness affect the compressive strength of hollow sandcrete blocks. Series arrangement of the cavities is common but parallel arrangement has been recommended. This research performed a comparative analysis of the compressive strength of cavities of different configurations. The test thin plate distributes the load on the block and the hollow block is regarded as a two way slab. The results showed that at equal end-web to centre-web thickness (1:2) and total cavity volume the stresses in the parallel configuration were higher than those in series configuration. The minimum stresses in the series arrangement were lower than the corresponding values in the parallel arrangement. In addition, the maximum stresses in the series arrangement were lower than the corresponding values for parallel arrangement. The implication is that at same volume and number of cavities and web thickness, the series arrangement results induced least stress.
\end{abstract}

Keywords: hollow sandcrete blocks, cavity size, cavity number, series arrangements, parallel arrangements, stresses

\section{INTRODUCTION}

Sandcrete blocks, moulded into different sizes [1], are often used as wall construction materials for buildings. Building industries in Nigeria often produce two-cell hollow sandcrete blocks [2], [3], but it is important that other configurations and sizes should be investigated, especially as they affect the compressive strength of sandcrete.

Some research work had been done on the relationship between cavity characteristics, web thickness and strength. The variations in cavity volumes, cavity shape, shell thickness and web thickness affect the compressive strength of hollow blocks. Ezeokonkwo [4] determined the influence of geometry on the compressive of hollow sandcrete blocks Results showed that specimen geometry affects the compressive strength of hollow sandcrete blocks significantly.

Ezeokonkwo showed that centre-web to end-web ratio of unity does not give hollow concrete blocks of maximum compressive strength. In addition, investigating the strength properties of two-cell hollow sandcrete blocks, he stated that the size of the block cavity would affect its compressive strength [4], [5]. His experimental results showed that there exists an optimum combination of cavity volume with centre-web ratio that would give the maximum strength. Not much investigation has been done on the relationship between the size and number of cavities and web thickness on one hand and their effects on the compressive strength of hollow sandcrete blocks on the other hand. The theoretical optimum cavity size, web thickness and cavity number that would yield the highest strength was investigated by Agunwamba et al. [6]. The hollow blocks were analysed as two-way slabs and the loads on the web and shell determined. The stresses were found by dividing the load by the corresponding areas. They observed that for a series arrangement the least stress $\left(0.5 \mathrm{~N} / \mathrm{mm}^{2}\right)$ was obtained when the cavity length, number and end web thickness were $50 \mathrm{~mm}, 4$ and $50 \mathrm{~mm}$ respectively. However, the total cavity volume was not kept constant. The use of parallel configuration has been suggested but has not been 
investigated. The essence of this research is to perform a comparative analysis between the compressive strengths of series and parallel configurations of hollow sandcrete blocks at constant cavity volume.

\section{MATHEMATICAL ANALYSIS}

The approach was to select the web thickness for each configuration and number of cavities that will result in equal total volume of the cavities.

\subsection{Selection of End web Thickness}

Consider the series (a) and parallel configuration (b) for 1, 4 and 9 cavities shown in Fig. 1. Obviously, the bigger the number of cavities, the smaller the web thickness since the total volume is kept constant.
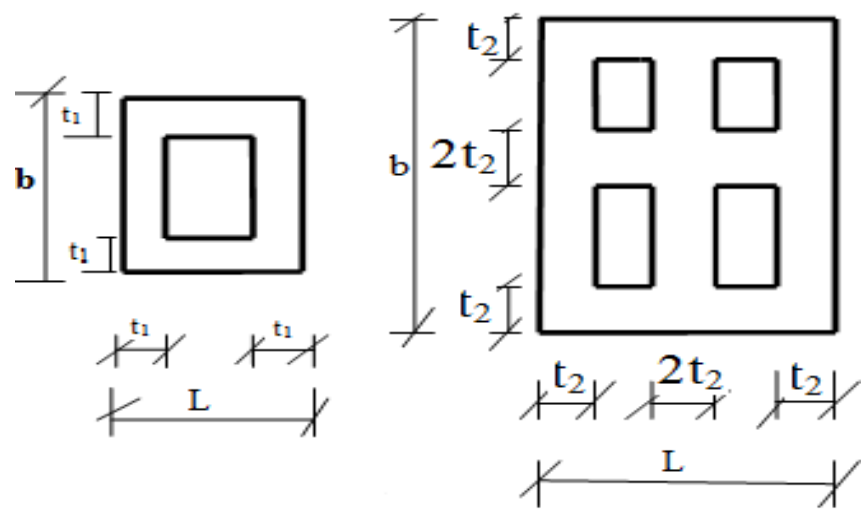

(a) Series
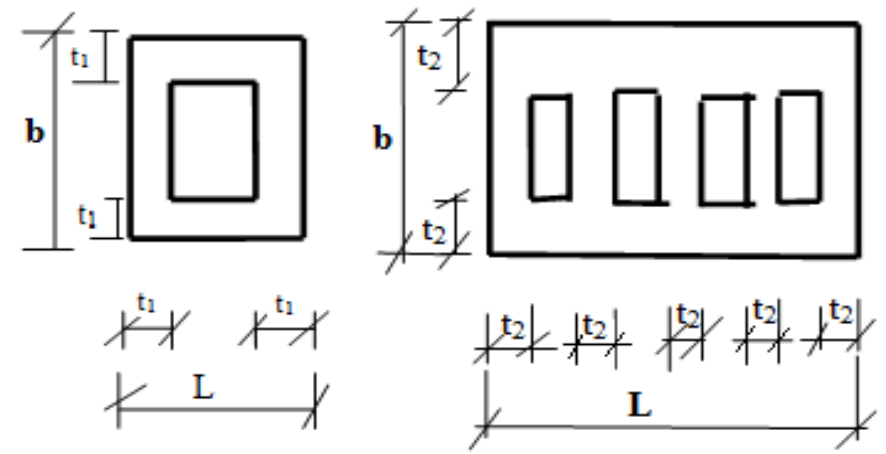

(b) Parallel

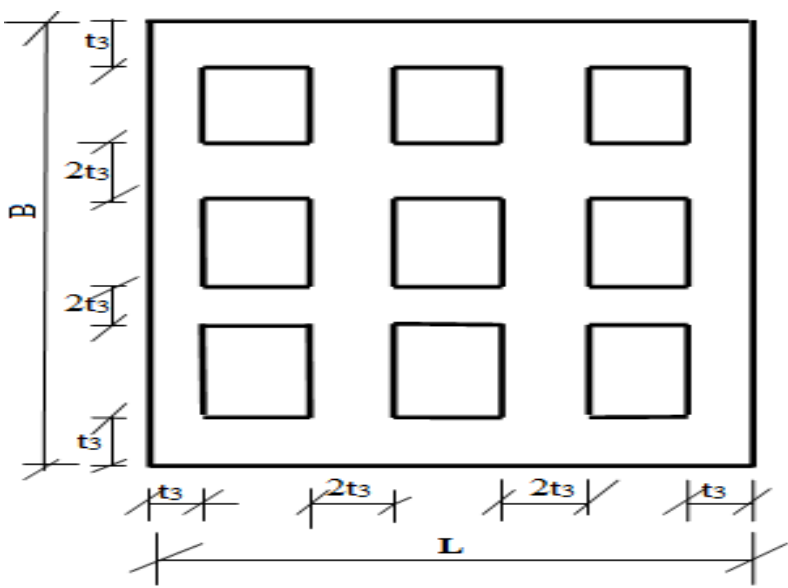

(c) Series

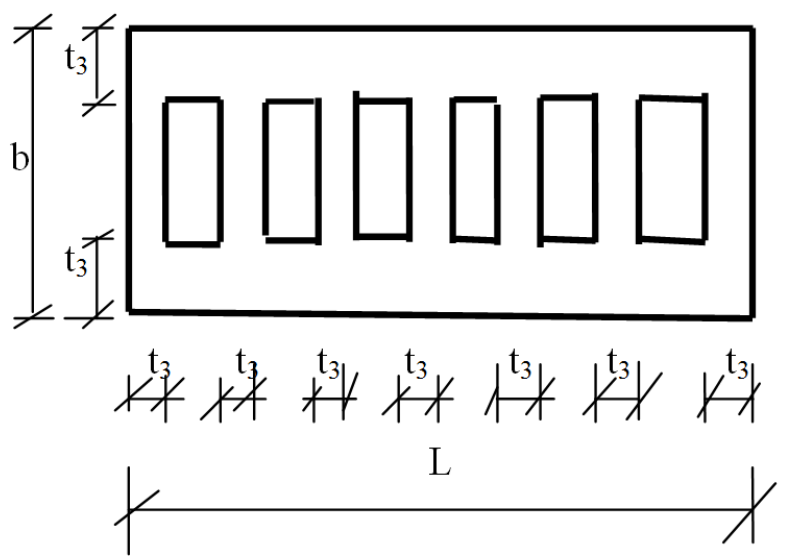

(d) Parallel

Fig. 1: Hollow sandcrete blocks with different number of cavities and configurations.

Area of void for parallel and series arrangement are equal for constant number of void.

\section{For 4 voids}

Area of void for parallel configuration

$=\left(\mathrm{b}-4 \mathrm{t}_{2 \mathrm{p}}\right)\left(\mathrm{L}-4 \mathrm{t}_{2 \mathrm{p}}\right)=\mathrm{A}_{\mathrm{p}}$

Area of void for series configuration

$=\left(\mathrm{b}-2 \mathrm{t}_{2 \mathrm{~s}}\right)\left(\mathrm{L}-8 \mathrm{t}_{2 \mathrm{~s}}\right)=\mathrm{A}_{\mathrm{s}}$

But $A_{p}=A_{s}$ for meaningful comparison

$=\mathrm{bL}-4 \mathrm{t}_{2 \mathrm{p}}(\mathrm{b}+\mathrm{L})+16 \mathrm{t}_{2 \mathrm{p}}{ }^{2}=\mathrm{bL}-2 \mathrm{t}_{2 \mathrm{~s}} \mathrm{~L}-8 \mathrm{bt} \mathrm{t}_{2 \mathrm{~s}}+16 \mathrm{t}_{2 \mathrm{~s}}{ }^{2}$

$=4 \mathrm{t}_{2 \mathrm{p}}\left[-(\mathrm{b}+\mathrm{L})+4 \mathrm{t}_{2 \mathrm{p}}\right]=2 \mathrm{t}_{2 \mathrm{~s}}\left[8 \mathrm{t}_{2 \mathrm{p}}-(\mathrm{L}+4 \mathrm{~b})\right]$

Let $\mathrm{t}_{2 \mathrm{p}}=50 \mathrm{~mm}, \mathrm{~b}=225 \mathrm{~mm}$ and $\mathrm{L}=450 \mathrm{~mm}$

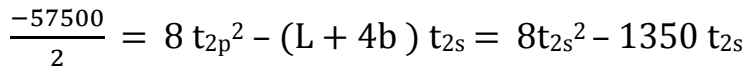

$\mathrm{t}_{2 \mathrm{~s}}=50 \mathrm{~mm}$ or $118.75 \mathrm{~mm}$

Select $50 \mathrm{~mm}$. The value $118.75 \mathrm{~mm}$ is too high

\section{For 9 voids}

$A_{p}=\left(b-6 t_{3 p}\right)\left(L-6 t_{3 p}\right)(3)$

$A_{s}=\left(b-2 t_{3 s}\right)\left(L-18 t_{3 s}\right)(4)$

Following the previous logic, 
$\mathrm{bL}-6 \mathrm{Lt}_{3 p}-6 b t_{3 p}+36 \mathrm{t}_{3 p^{2}}$

$\left.\Rightarrow \quad 6 \mathrm{t}_{3 \mathrm{P}}\left[-(\mathrm{b}+\mathrm{L})+6 \mathrm{t}_{3 \mathrm{p}}\right]=2 \mathrm{t}_{3 \mathrm{~s}}-(\mathrm{L}+9 \mathrm{~b})\right]$

If $\mathrm{t}_{3 \mathrm{p}}=33.33 \mathrm{~mm}, \mathrm{~b}=225 \mathrm{~mm}$ and $\mathrm{L}=450 \mathrm{~mm}$,

Then the above equation simplifies to

$18 t_{3 s^{2}}-2475 t_{3 s}+47500=0$

$\Rightarrow \quad t_{3 \mathrm{~s}} \approx 23 \mathrm{~mm}$

The values of the end web thicknesses obtained from parallel and series arrangement are given in Table 1.

\subsection{Determination of the Stresses}

The stresses were determined by regarding the hollow sandcrete block as rectangular panels freely supported along the sides with load. This stimulates approximately the condition of the hollow sandcrete blocks during loading. Samples of the calculations are shown below and in Tables 2and 3. The calculations below shows the panels supported along one or more edges while Table 2 and 3 depict the computation of the stresses for end web to centre web ratios of $1: 1$ and $1: 2$ respectively.

Determination of the values of $\mathrm{R}$ (Newton) for the panels supported along one or more edges are shown below. $\mathrm{W}$ is the typical load carried by the hollow sandcrete block and obtained from Reynolds et al. [7]. The supports are treated as simply support and fixed support and depends on the position of the cavity. $\mathrm{R}$ is reaction at support. The value $\mathrm{k}$ is a ratio and how to obtain it is given below.

(1)

$$
\begin{aligned}
& 225 \text { R1 } R \text { R3 } \\
& k=\frac{L y}{L x}=\frac{450}{225}=2 \\
& R_{1}=R_{3}=\frac{1}{4} w l x^{2}=\frac{1}{4} \times 1.8469 \times 225^{2} \\
& =23374.8 \\
& R_{2}=R_{4}=\frac{1}{2}\left(k-\frac{1}{2}\right) w l x_{2} \\
& =\frac{1}{2}\left(2-\frac{1}{2}\right) \times 1.8469 \times 225^{2} \\
& =701224.5
\end{aligned}
$$

$$
\begin{aligned}
& \mathrm{R} 1 \mathrm{R}^{\mathrm{R} 2} \\
& k=\frac{L y}{L x}=\frac{225}{112.5}=2 \\
& R_{1}=\frac{3}{16} w l x^{2}=\frac{3}{16} \times 1.8469 \times 225^{2}=4382.8 \\
& R_{4}=\frac{5}{8}\left(k-\frac{1}{2}\right) w l x^{2} \\
& =\frac{5}{8}\left(2-\frac{1}{2}\right) \times 1.8469 \times 225^{2} \\
& =9739.5 \\
& R_{2}=\frac{3}{5} R_{4}=\frac{3}{5} \times 21913.9=13148.3 \\
& R_{3}=\frac{5}{16} w l x^{2}=\frac{5}{16} \times 1.8469 \times 225^{2}=7304.6 \\
& \text { (3) } \\
& k=\frac{L y}{L x}=\frac{150}{75}=2 \\
& R_{1}=\frac{3}{16} w l x^{2}=\frac{3}{16} \times 1.8469 \times 75^{2}=1947.9 \\
& R_{3}=\frac{5}{16} w l x^{2}=\frac{5}{16} \times 1.8469 \times 75^{2}=3246.5 \\
& R_{4}=\frac{5}{8}\left(k-\frac{1}{2}\right) w l x^{2} \\
& =\frac{5}{8}\left(2-\frac{1}{2}\right) \times 1.8469 \times 75^{2} \\
& =9739.5 \\
& R^{2}=\frac{3}{5} R_{4}=\frac{3}{5} \times 21913.9=5843.7 \\
& k=\frac{L y}{L x}=\frac{150}{75}=2 \\
& R_{4}=\frac{5}{8}\left(2-\frac{5}{8}\right) w l x^{2}=\frac{5}{8}\left(2-\frac{5}{8}\right) \times 1.8469 \times 75^{2} \\
& =16488.9 \\
& R_{1}=R_{3}=\frac{5}{16} w l x^{2}=\frac{5}{16} \times 1.8469 \times 75^{2} \\
& =3246.5
\end{aligned}
$$
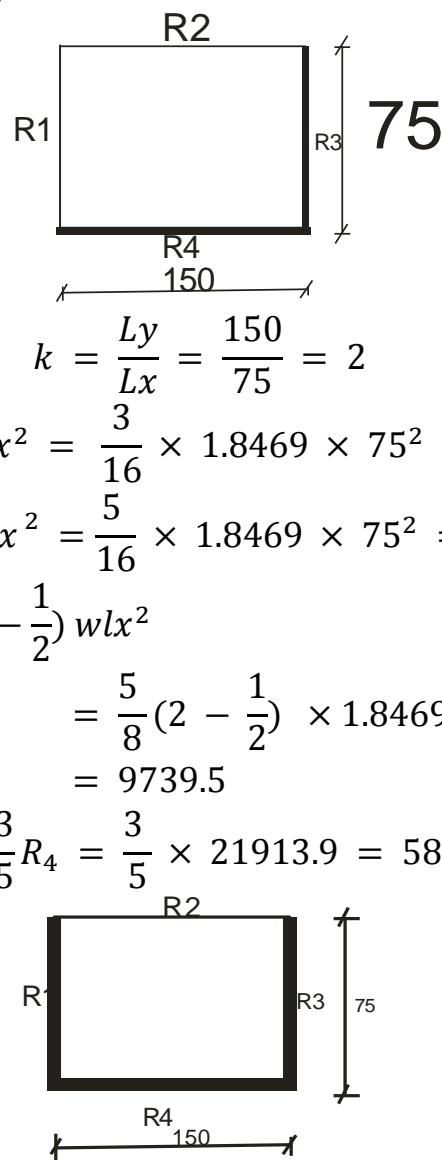


$$
\begin{aligned}
& R_{2}=\frac{3}{5} R_{4}=\frac{3}{5} \times 16488.9=9893.3
\end{aligned}
$$

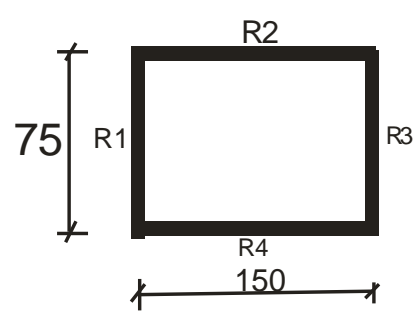

$$
\begin{aligned}
& k=\frac{L y}{L x}=\frac{150}{75}=2 \\
& R_{1}=R_{3}=\frac{1}{4} w l x^{2}=\frac{1}{4} \times 1.8469 \times 752 \\
& =2597.2 \\
& R_{2}=R_{4}=\frac{1}{2}\left(k-\frac{1}{2}\right) w l x^{2} \\
& =\frac{1}{2}\left(2-\frac{1}{2}\right) \times 1.8469 \times 75^{2} \\
& =7791.6 \\
& 75 \text { R1 } \\
& k=\frac{L y}{L x}=\frac{150}{75}=2 \\
& R_{1}=\frac{3}{20} w l x^{2}=\frac{3}{20} \times 1.8469 \times 75^{2}=1558.3 \\
& R_{2}=R_{4}=\frac{1}{2}\left(k-\frac{2}{5}\right) w l x^{2} \\
& =\frac{1}{2}\left(2-\frac{2}{5}\right) \times 1.8469 \times 75^{2} \\
& =83111 \text {. } \\
& R_{2}=\frac{1}{4} w l x^{2}=\frac{1}{4} \times 1.8469 \times 75^{2}=2597.2
\end{aligned}
$$

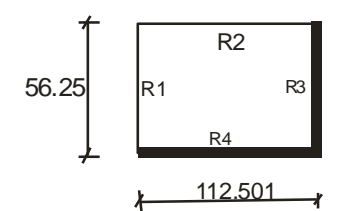

$$
k=\frac{L y}{L x}=\frac{112.501}{56.25}=2
$$

$R_{1}=\frac{3}{16} w l x^{2}=\frac{3}{16} \times 1.8469 \times 56.25^{2}=1095.7$

$R_{3}=\frac{5}{16} w l x^{2}=\frac{5}{16} \times 1.8469 \times 56.25^{2}=1826.2$

$$
\begin{aligned}
& R_{4}=\frac{5}{8}\left(k-\frac{1}{2}\right) w l x^{2} \\
&= \frac{5}{8}\left(2-\frac{1}{2}\right) \times 1.8469 \times 56.25^{2} \\
&= 5478.5 \\
& R_{2}=\frac{3}{5} R_{4}=\frac{3}{5} \times 5478.5=3287.1
\end{aligned}
$$$$
\text { (4) }
$$

$$
\begin{aligned}
& \text { †6.25 } \begin{array}{lll} 
& \mathrm{R} 2 & \\
\mathrm{R} 1 & & \mathrm{R} 3 \\
& \mathrm{R} 4 & \\
& &
\end{array} \\
& \text { 1 } 112.501 \longrightarrow \\
& k=\frac{L y}{L x}=\frac{112.501}{56.25}=2 \\
& R_{1}=\frac{3}{20} w l x^{2}=\frac{3}{20} \times 1.8469 \times 56.25^{2}=876.3 \\
& R_{2}=R_{4}=\frac{1}{2}\left(k-\frac{2}{5}\right) w l x^{2} \\
& =\frac{1}{2}\left(2-\frac{2}{5}\right) \times 1.8469 \times 56.25^{2} \\
& =4675 \\
& R_{3}=\frac{1}{4} w l x^{2}=\frac{1}{4} \times 1.8469 \times 56.25^{2}=1460.9 \\
& 56.25 \text { R1 }^{\mathrm{R}^{\mathrm{R} 2}}{ }^{\mathrm{R3}} \\
& k=\frac{L y}{L x}=\frac{112.501}{56.25}=2 \\
& R_{4}=\frac{5}{8}\left(k-\frac{5}{8}\right) w l x^{2} \\
& =\frac{5}{8}\left(2-\frac{5}{8}\right) \times 1.8469 \times 56.25^{2} \\
& =5021.9 \\
& R_{1}=R_{3}=\frac{5}{16} w l x^{2}=\frac{5}{16} \times 1.8469 \times 56.25^{2} \\
& =1826.2 \\
& R_{2}=\frac{3}{5} R_{4}=\frac{3}{5} \times 5021.9=3013.1
\end{aligned}
$$

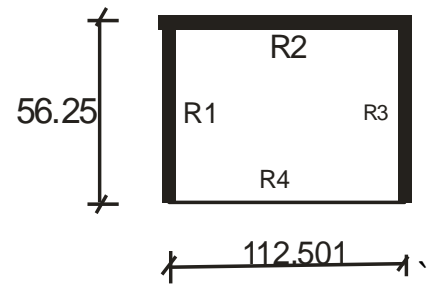




$$
\begin{aligned}
& k=\frac{L y}{L x}=\frac{112.501}{56.25}=2 \\
& R_{1}=R_{3}=\frac{1}{4} w l x^{2}=\frac{1}{4} \times 1.8469 \times 56.25^{2} \\
& =1460.2 \\
& R_{2}=R_{4}=\frac{1}{2}\left(k-\frac{1}{2}\right) w l x^{2} \\
& =\frac{1}{2}\left(2-\frac{1}{2}\right) \times 1.8469 \times 56.25^{2} \\
& =4382.8 \\
& k=\frac{L y}{L x}=\frac{90.001}{45}=2 \\
& R_{1}=\frac{3}{16} w l x^{2}=\frac{3}{16} \times 1.8469 \times 56.25^{2}=701.2 \\
& R_{3}=\frac{5}{16} w l x^{2}=\frac{5}{16} \times 1.8469 \times 45^{2}=1168.7 \\
& R_{4}=\frac{5}{8}\left(k-\frac{1}{2}\right) w l x^{2} \\
& =\frac{5}{8}\left(2-\frac{1}{2}\right) \times 1.8469 \times 45^{2} \\
& =3506.2 \\
& R_{2}=\frac{3}{5} R_{4}=\frac{3}{5} \times 3506.2=2103.7 \\
& k=\frac{L y}{L x}=\frac{90.001}{45}=2 \\
& R_{4}=\frac{5}{8}\left(k-\frac{5}{8}\right) w l x^{2} \\
& =\frac{5}{8}\left(2-\frac{5}{8}\right) \times 1.8469 \times 45^{2} \\
& =3214.0 \\
& R_{1}=R_{3}=\frac{5}{16} w l x^{2}=\frac{5}{16} \times 1.8469 \times 45^{2} \\
& =1168.7 \\
& R_{2}=\frac{3}{5} R_{4}=\frac{3}{5} \times 3214.0=1928.4
\end{aligned}
$$
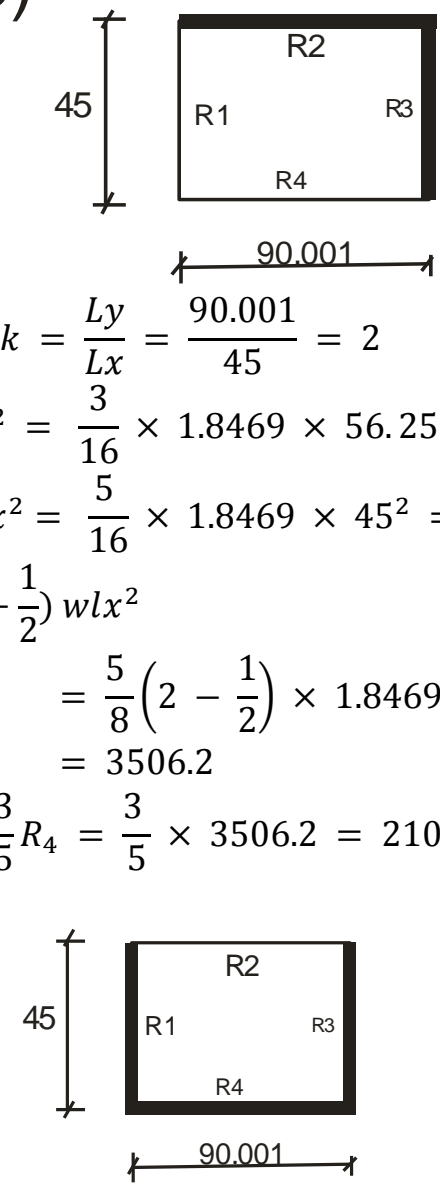

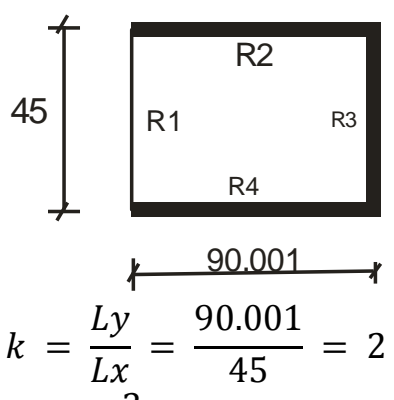

$$
R_{1}=\frac{3}{20} w l x^{2}=\frac{3}{20} \times 1.8469 \times 45^{2}=561.0
$$$$
R_{2}=R_{4}=\frac{1}{2}\left(k-\frac{2}{5}\right) w l x^{2}
$$$$
=\frac{1}{2}\left(2-\frac{2}{5}\right) \times 1.8469 \times 45^{2}
$$$$
=2992.0
$$$$
R_{3}=\frac{1}{4} w l x^{2}=\frac{1}{4} \times 1.8469 \times 45^{2}=935.0
$$

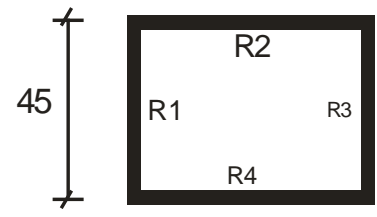

90.001

$$
k=\frac{L y}{L x}=\frac{90.001}{45}=2
$$$$
R_{1}=R_{3}=\frac{1}{4} w l x^{2}=\frac{1}{4} \times 1.8469 \times 45^{2}=935.0
$$$$
R_{2}=R_{2}=\frac{1}{2}\left(k-\frac{1}{2}\right) w l x^{2}
$$$$
=\frac{1}{2}\left(2-\frac{1}{2}\right) \times 1.8469 \times 37.5^{2}
$$$$
=2805.0
$$

(6)

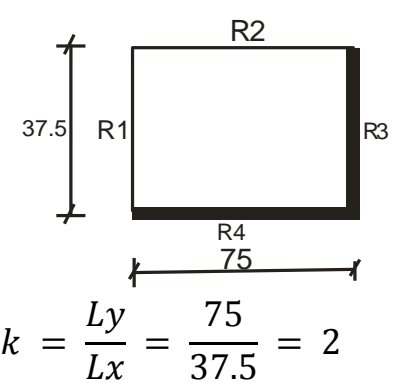

$R_{1}=\frac{3}{16} w l x^{2}=\frac{3}{16} \times 1.8469 \times 37.5^{2}=487.0$

$R_{3}=\frac{5}{16} w l x^{2}=\frac{5}{16} \times 1.8469 \times 37.5^{2}=811.6$ $R_{4}=\frac{5}{8}\left(k-\frac{1}{2}\right) w l x 2^{2}$

$$
\begin{aligned}
= & \frac{5}{8}\left(2-\frac{1}{2}\right) \times 1.8469 \times 37.5^{2} \\
= & 2434.9 \\
R_{2}=\frac{3}{5} R_{4} & =\frac{3}{5} \times 2434.9=1460.9
\end{aligned}
$$




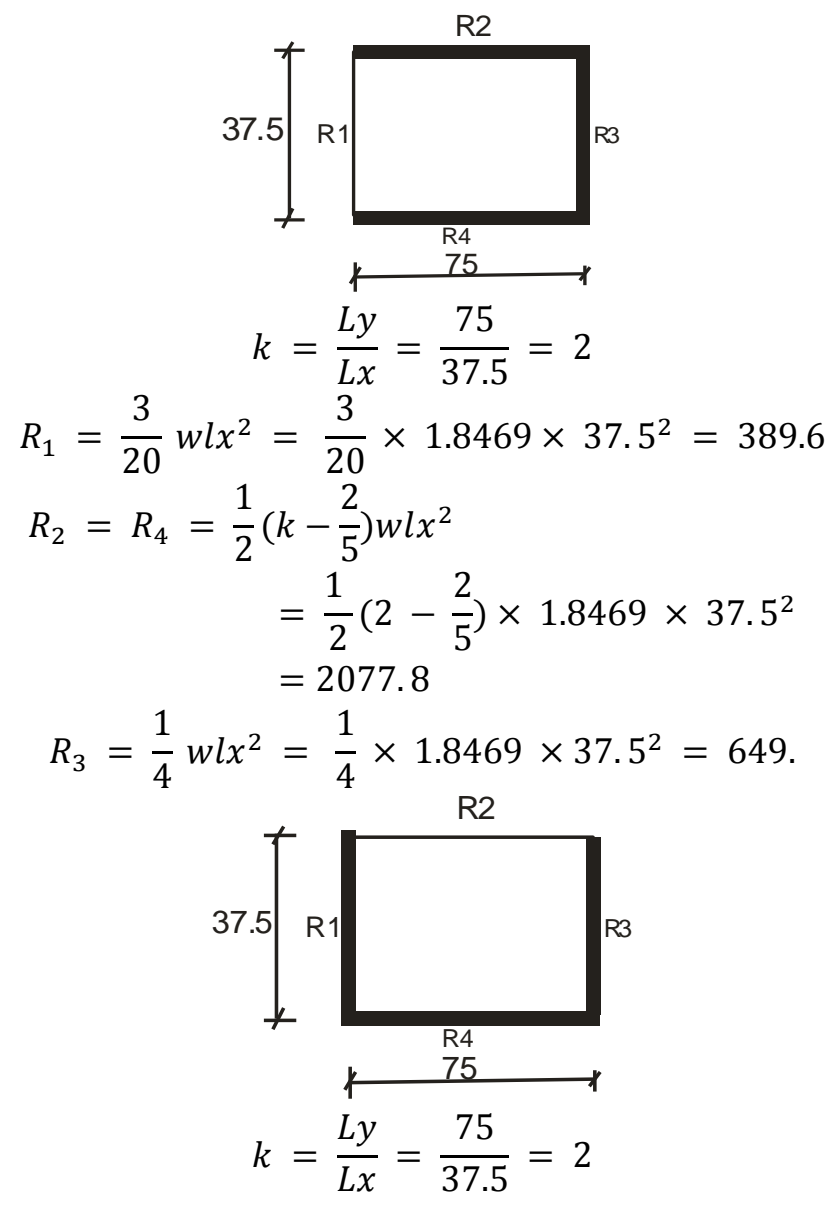

$$
\begin{aligned}
& R_{4}=\frac{5}{8}\left(k-\frac{5}{8}\right) w l x^{2} \\
& =\frac{5}{8}\left(2-\frac{5}{8}\right) \times 1.8469 \times 37.5^{2} \\
& =2232.0 \\
& R_{1}=R_{3}=\frac{5}{16} w l x^{3}=\frac{5}{16} \times 1.8469 \times 37.5^{3} \\
& =811.6 \\
& R_{2}=\frac{3}{5} R_{4}=\frac{3}{5} \times 2232=1339.2
\end{aligned}
$$

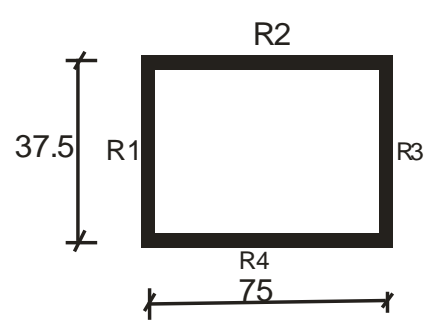

$$
\begin{aligned}
& k=\frac{L y}{L x}=\frac{75}{37.5}=2 \\
& R_{1}=R_{3}=\frac{1}{4} w l x^{2}=\frac{1}{4} \times 1.8469 \times 37.5^{2} \\
& =649.3 \\
& R_{2}=R_{4}=\frac{1}{2}\left(k-\frac{1}{2}\right) w l x^{2} \\
& =\frac{1}{2}\left(2-\frac{1}{2}\right) \times 1.8469 \times 37.5^{2} \\
& =1947.9
\end{aligned}
$$

Table 2: Computation of stress for 1:1

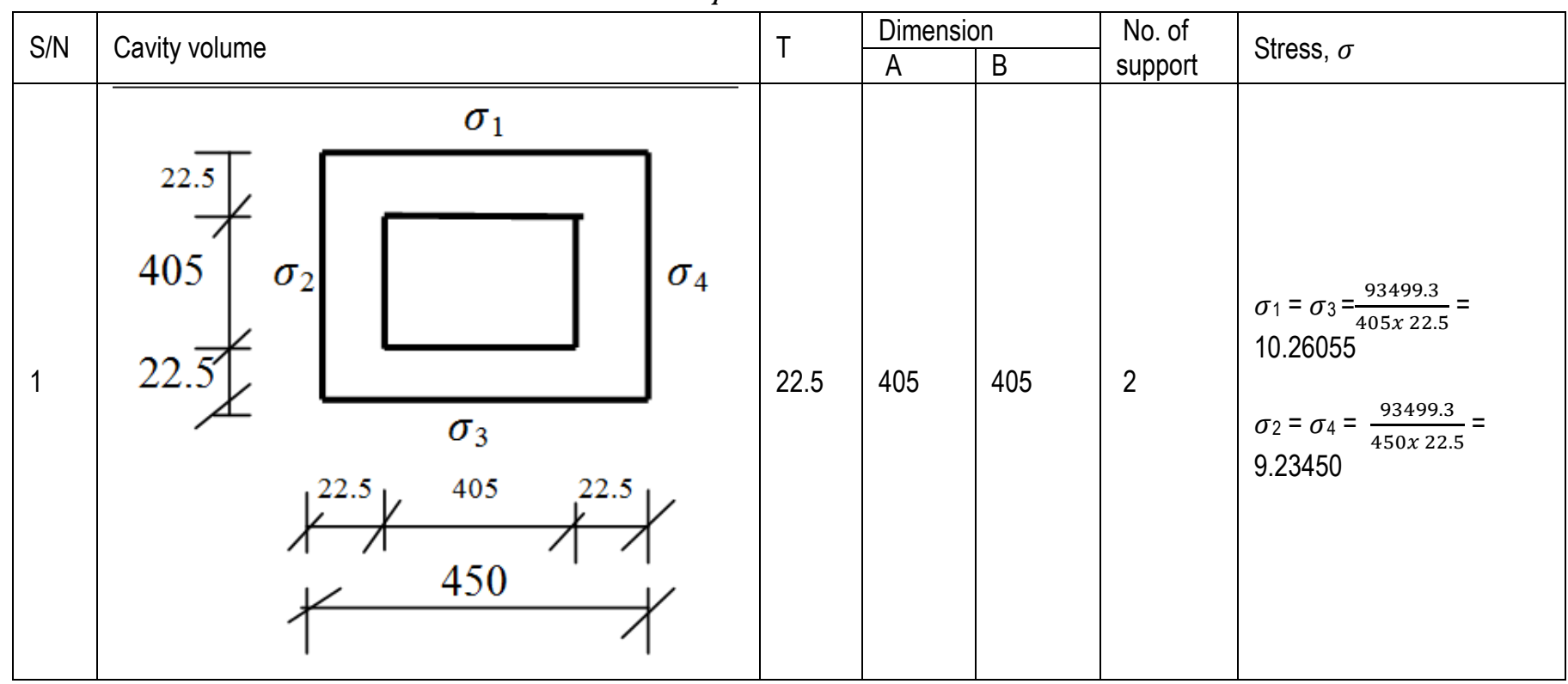




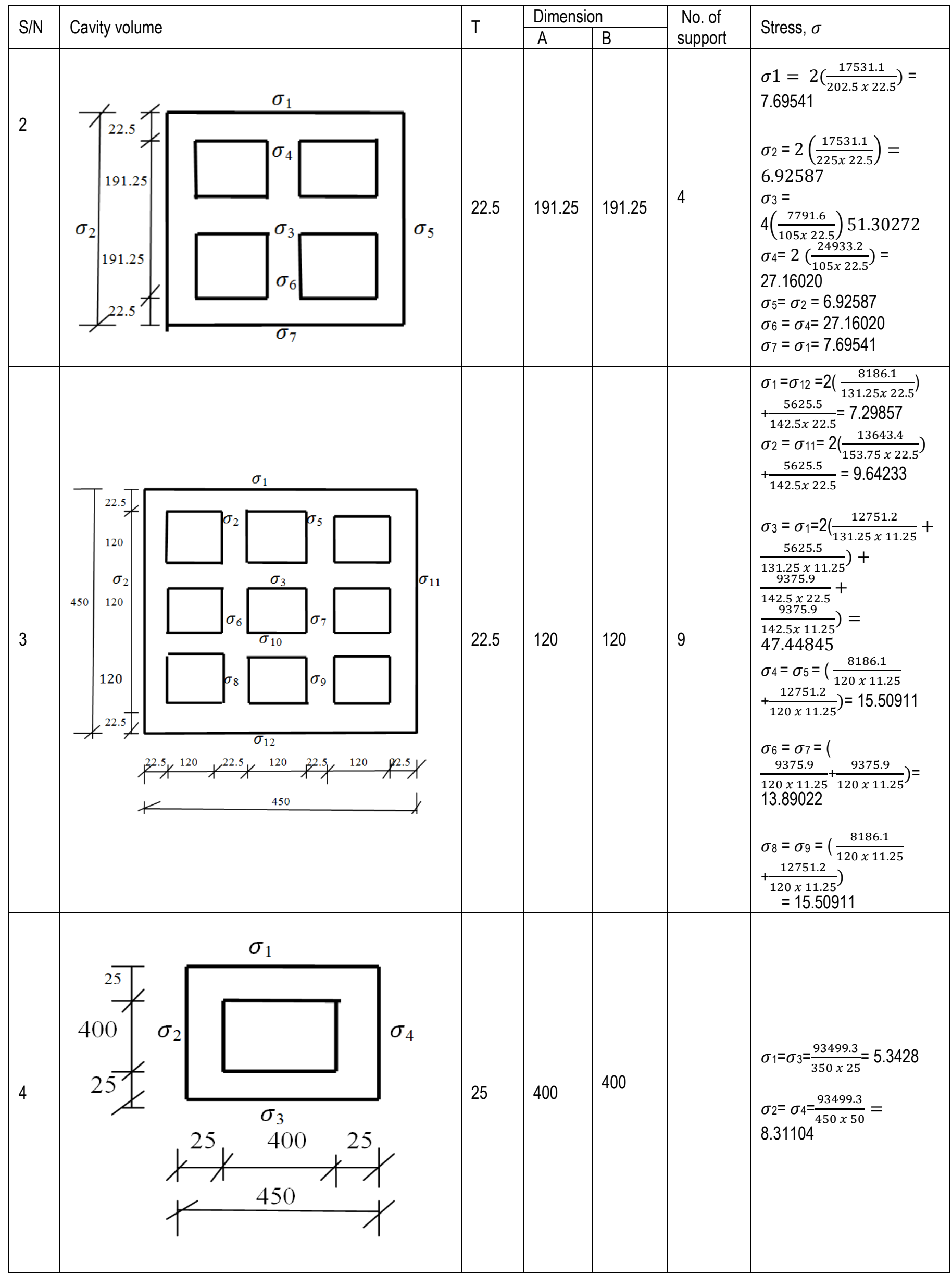




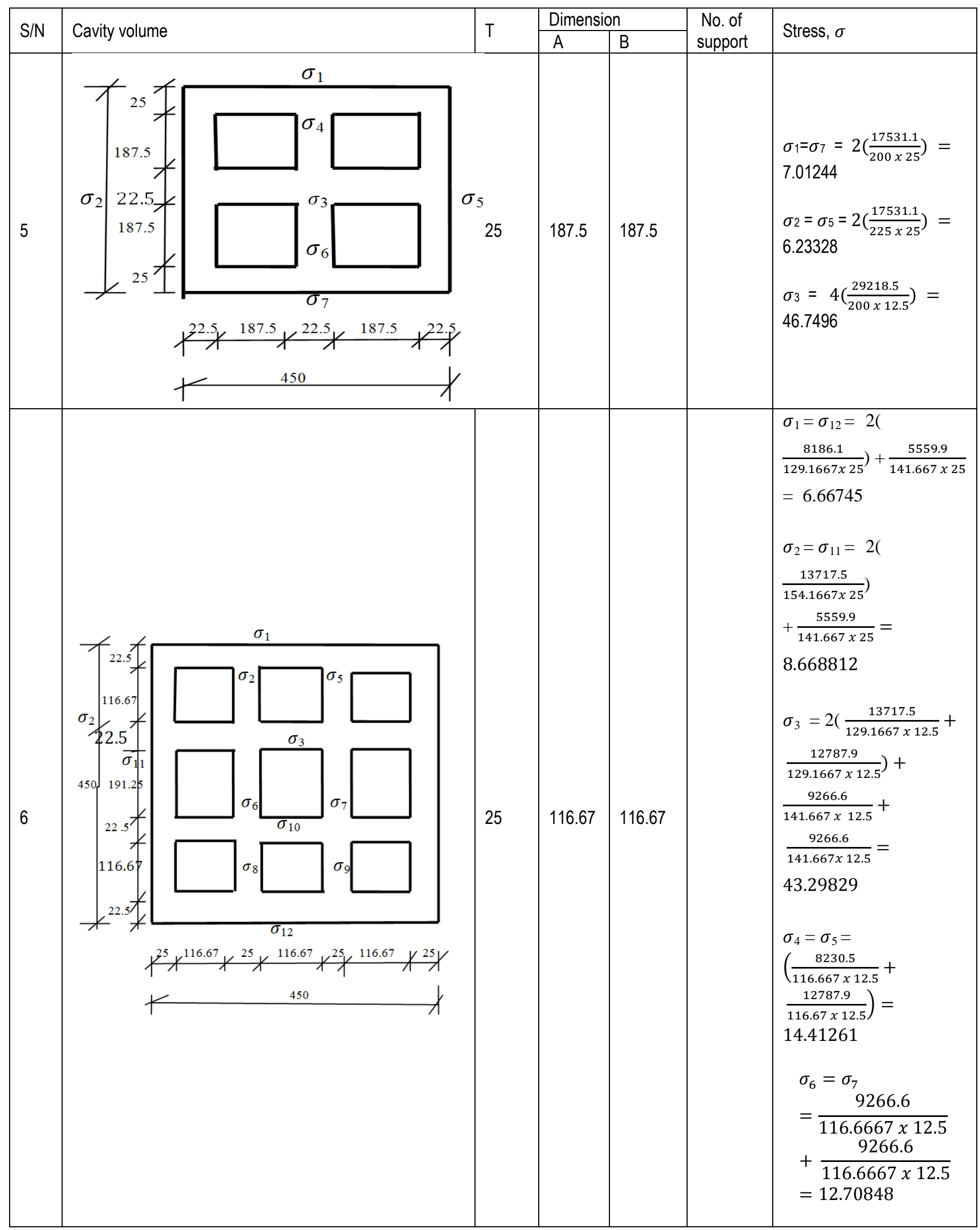




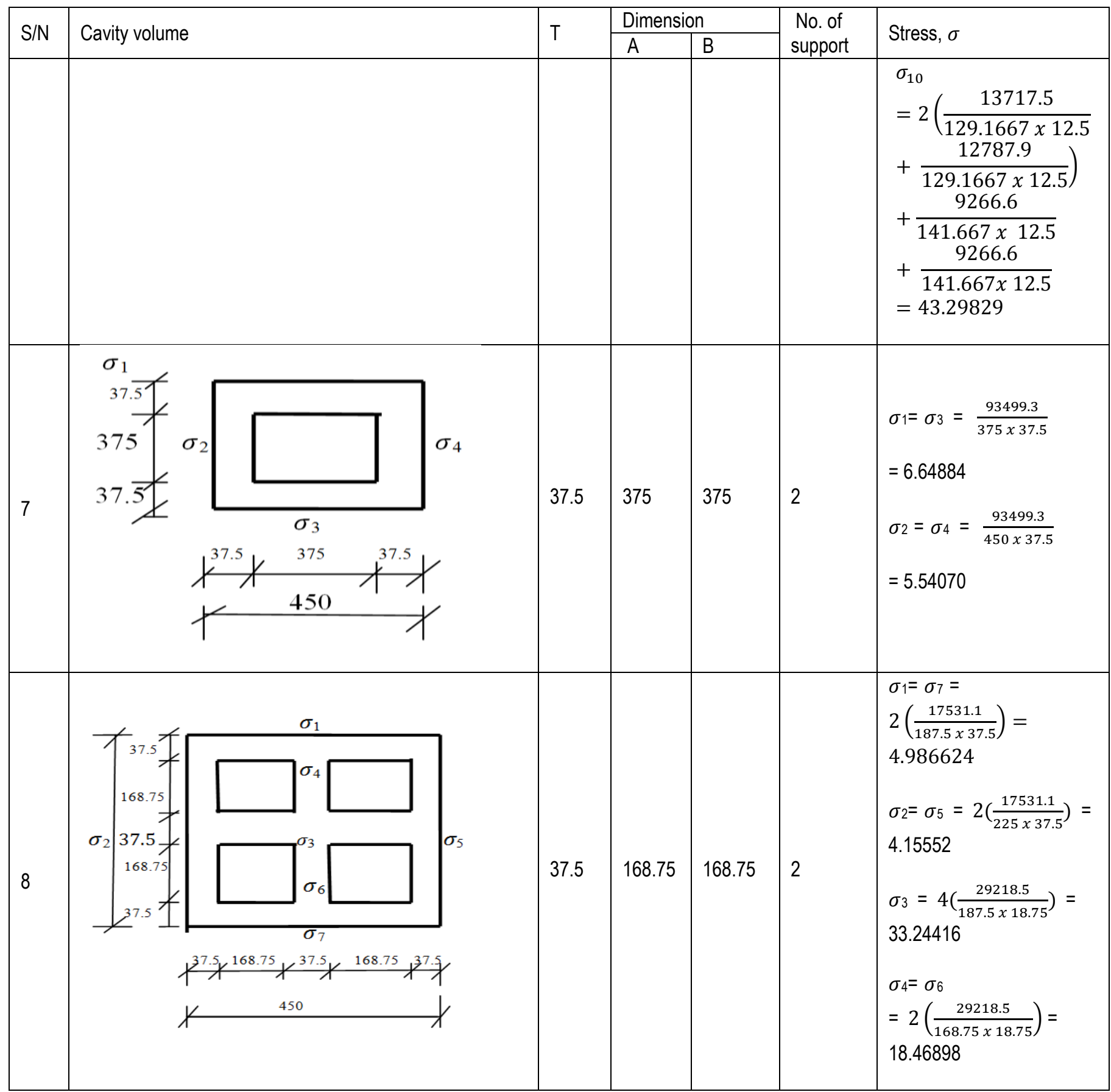




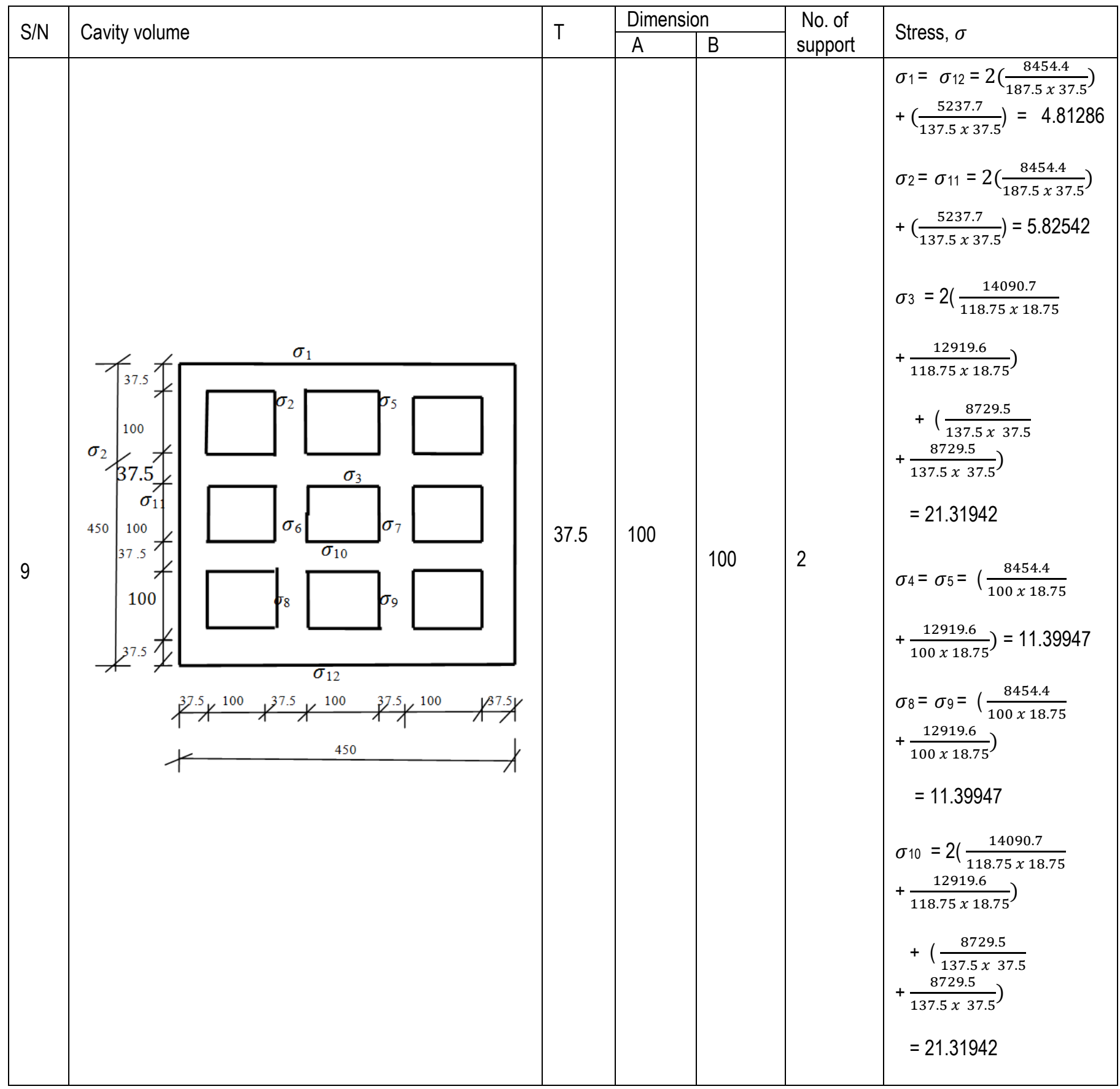


Table 3: Computation of stress for 1:2

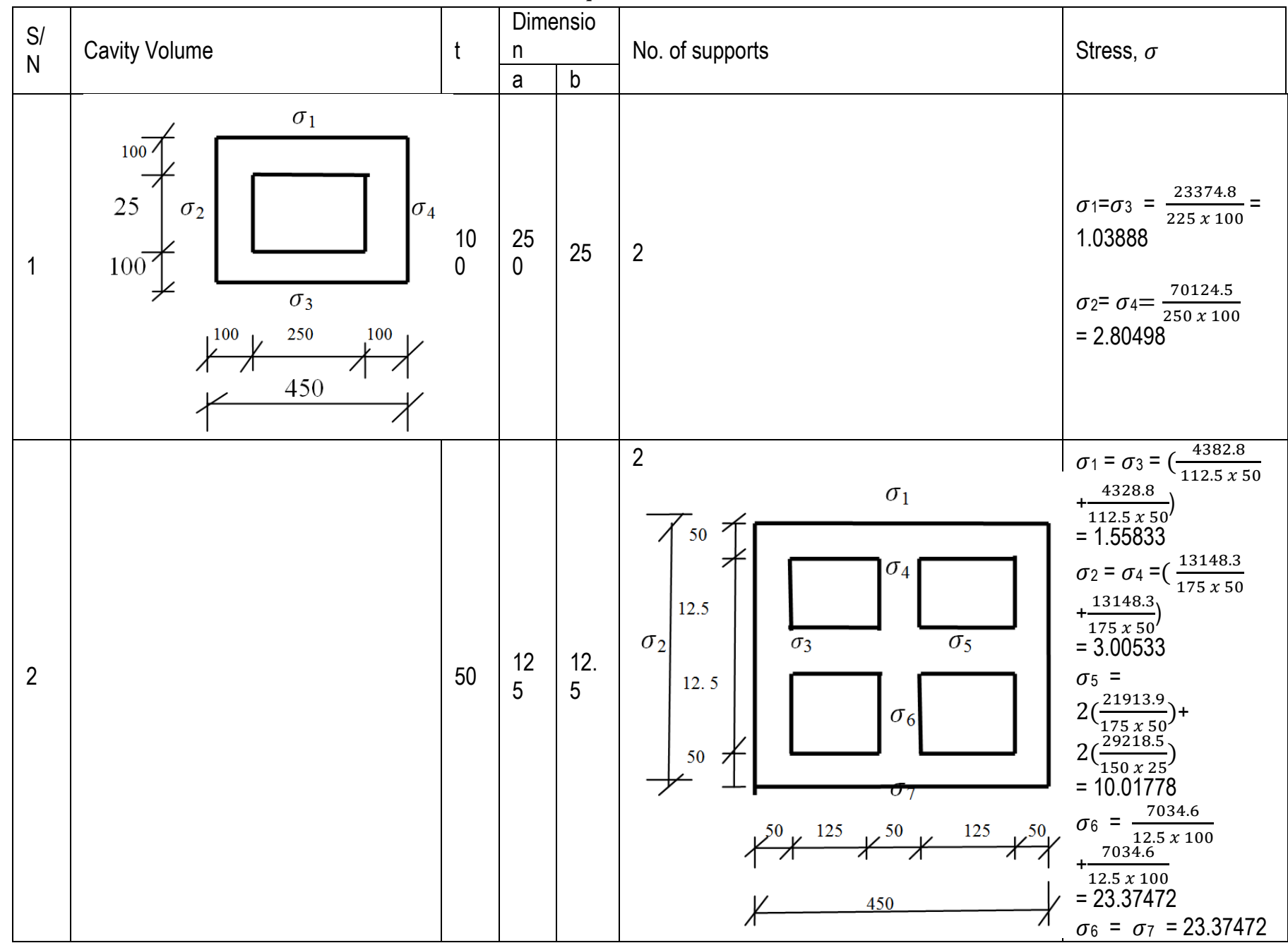

\section{RESULT AND DISCUSSION}

3.1 Effect of web thickness on stress (End-web: Centre web thickness of 1:1)

The effect of web thickness on maximum stress is shown in Table 2 for 1, 4 and 9 cavities in parallel arrangement. The highest maximum stresses at $22.5 \mathrm{~mm}, 25 \mathrm{~mm}, 37.5 \mathrm{~mm}$ and $50 \mathrm{mmweb}$ thickness were $51.3 \mathrm{~N} / \mathrm{mm}^{2}, 46.8 \mathrm{~N} / \mathrm{mm}^{2}, 33.2 \mathrm{~N} / \mathrm{mm}^{2}$ and $26.7 \mathrm{~N} / \mathrm{mm}^{2}$ respectively and occurred when the number of cavity was 4 . The corresponding lowest stresses were $6.9 \mathrm{~N} / \mathrm{mm}^{2}, 6.2 \mathrm{~N} / \mathrm{mm}^{2}, 4.2 \mathrm{~N} / \mathrm{mm}^{2}$ and $3.1 \mathrm{~N} / \mathrm{mm}^{2}$ respectively and also occurred for 4 numbers of cavities. The best configuration was the one that induced the lowest maximum stress in the system i.e. $5.3 \mathrm{~N} / \mathrm{mm}^{2}$ when $\mathrm{n}=1$ and $\mathrm{t}=50 \mathrm{~mm}$ (see Fig 2).

\subsection{Effect of web thickness on stress (End-web: Centre - web thickness of 1:2)}

The least maximum stress $2.81 \mathrm{~N} / \mathrm{mm}^{2}$ occurs at $\mathrm{t}_{\mathrm{mm}}=$ $100 \mathrm{~mm}$ and $\mathrm{n}=1$. This configuration also yielded the lowest stress of $1.04 \mathrm{~N} / \mathrm{mm}^{2}$ in the system (Table 3 and Fig. 3).

Hence, with respect to parallel arrangement, where the total volume of the cavities are equal, the least stress was given when the number of cavities is 1 at $t$ $=100 \mathrm{~mm}$.

Table 4: The lowest and maximum compressive stresses for Series and Parallel Arrangement

\begin{tabular}{cccccc}
\hline \multirow{2}{*}{$\begin{array}{c}\text { No. of } \\
\text { cavities }\end{array}$} & \multicolumn{2}{c}{$\sigma_{\text {lowest }}\left(\mathrm{N}_{\mathrm{N} / \mathrm{mm}^{2}}\right)$} & \multicolumn{2}{c}{$\sigma_{\text {maximum }}\left(\mathrm{N} / \mathrm{mm}^{2}\right)$} & \multirow{2}{*}{$\mathrm{t}_{\mathrm{mm}}$} \\
\cline { 2 - 5 } & series & Parallel & series & parallel & \\
\hline 1 & 1.039 & 1.039 & 2.805 & 2.805 & 100 \\
4 & 1.266 & 1.558 & 7.013 & 23.375 & 50 \\
9 & 1.144 & 2.182 & 6.242 & 14.139 & 33.33 \\
9 & 1.4103 & & 7.695 & & \\
16 & $\mathrm{t}=22.5$ & $\mathrm{t}=33.33$ & $\mathrm{t}=22.5$ & $\mathrm{t}=33.33$ & \\
& 0.612 & 2.805 & 13.523 & 23.375 & 25 \\
\hline
\end{tabular}

\subsection{Comparison between the Stresses Induced in Series and Parallel Arrangements}

The lowest and maximum stresses induced in the series and parallel configurations at different equal 
end web thickness and ratio 1:1 at equal total cavity volumes are shown in Table 4.

The stresses in the series arrangement were always greater than the corresponding values obtained for parallel arrangement. Hence, the series configuration is better. In addition, the series arrangement gave the overall least stress $\left(0.61 \mathrm{~N} / \mathrm{mm}^{2}\right)$ at $\mathrm{n}=16$. However, the maximum stress is $13.5 \mathrm{~N} / \mathrm{mm}^{2}$ and as argued previously by Agunwamba et al. [6], this configuration that is also associated with high stress, even though it yielded the least also cannot be the optimum. It will still result in a collapse since one of the members is highly stressed. In summary, the least maximum stress was obtained at $\mathrm{n}=1$ with a value of $2.81 \mathrm{~N} / \mathrm{mm}^{2}$.

\section{CONCLUSION AND RECOMMENDATION}

The study has shown that hollow sandcrete blocks may be analysed as panels supported along one or more edges under the assumptions that it possesses similar characteristics with concrete. While this is obviously not accurate, this approximate analysis can give some insight into the configurations that would induce the least stress in hollow sandcrete block members. The study has shown that series arrangement is better than parallel arrangement. In addition, there is no structural advantage in using more than one cavity provided the sum total of the cavity volumes is kept constant.
However, more research is needed with respect to investigating these findings experimentally. In addition more configurations and shapes should be analysed and compared with the results of this research and experiments.

\section{REFERENCES}

[1] Barry, R.. The construction of building Crosby Lockwood; London, Vol. 1, 54-55, 94, 1969.

[2] Hijab, M; Halilu, A. H. and Hadi, A. A.. Compressive strength of marketed sandcrete blocks produced in Yola, Nigeria. Journal of Engineering and Applied Science 2, 74-81, 2010.

[3] Anosike, M. N, Oyebade, A. A. Sandcrete blocks and quality management in Nigeria Building Industry. Journal. of Engineering Project and Production Management. 2 (1), 37- 46, 2012.

[4] Ezeokonkwo, J. C. Unaxial compressive strength of sandcrete hollow blocks and its dependence on geometry. M. Eng. Project Report. Dept. of Civil Engineering, UNN, pp 44- 77, 1988.

[5] Ezeokonkwo, J. C. Optimization of cavity size in hollow sandcrete blocks. Journal. of Engineering Trends in Engineering and Applied Sci. 3(1), 185 188, 2012.

[6] Agunwamba, J. C, Ezeokonkwo, J. C., Onyia, M. E., Ojiogu, E and Amadou, A. Theoretical investigation of stresses distribution in hollow sandcrete blocks due to variation of cavity sizes and number web thickness, Nigerian Journal of Technology, vol. 35, No. 2, April, 2016, pp. 254-259. 